\title{
Age-Related Differences in Reward-Based Modulation of Sequential Reaching Performance
}

\section{Poppy Aves ${ }^{1}$, Laura Moreau ${ }^{1}$, Ahmad Alghamdi ${ }^{1}$, Sebastian Sporn ${ }^{1,2}$ \& Joseph M Galea ${ }^{1}$}

${ }^{1}$ School of Psychology and Centre for Human Brain Health, University of Birmingham, UK

${ }^{2}$ Department of Clinical and Movement Neuroscience, Queens Square Institute of Neurology, UCL, UK

Conflict of Interest: The authors declare no competing financial interests

Acknowledgements: This work was supported by the European Research Council starting grant: MotMotLearn (637488)

\section{Correspondence:}

Joseph Galea Sebastian Sporn

Email: j.galea@bham.ac.uk 


\section{Abstract}

Reward can increase the speed and accuracy of movements in both simple and sequential reaching tasks. Two mechanisms are thought to be responsible for this: an increase in maximum velocity, due to increased muscle stiffness, resulting in faster, but energetically inefficient, individual movements; or coarticulation - the blending of sub-movements into single, smoother, more energetically efficient movements. Older adults have shown reduced sensitivity to reward in decision paradigms, but there is little research relating reward and motor performance in older adults. Using a novel online sequential reaching task, we compared the effects of reward on motor performance between young (18-23 years) and older (65-79 years) participants. We found that movement time decreased across training in all groups, and reward invigorated this decrease in both age groups. This suggests that reward is a viable facilitator of motor performance to compensate for age-related motor decline and has the potential for use in the design of rehabilitation programmes for age-related motor deficits or disease. 
bioRxiv preprint doi: https://doi. org/10.1101/2021.09.27.461920; this version posted September 27, 2021. The copyright holder for this preprint (which was not certified by peer review) is the author/funder, who has granted bioRxiv a license to display the preprint in perpetuity. It is made available under aCC-BY-NC-ND 4.0 International license.

\section{Introduction}

Sequential movements form a large part of everyday life. From taking a shower to chopping vegetables, many seemingly trivial daily tasks are made up of several distinct sub-movements $[1,2]$ blended into a continuous action for efficiency after learning [3]. As these types of movement are so critical for independence in everyday life, when age-related motor decline or age-related diseases such as stroke impact the motor system, it becomes necessary to improve performance.

Motor performance improvement is often assessed in terms of increases in speed and accuracy. One method of enhancing motor performance that has been relatively well studied is the application of reward. Seeking reward can induce feelings of pleasure, acting as positive reinforcement, and therefore can be a powerful tool when looking to shape goal-directed behaviour [4]. Human motor behaviour acts on a speed-accuracy trade off, hence, as movements get faster, they decrease in accuracy and vice versa. However, previous work has suggested that reward can be utilised to shift this speed-accuracy function for both saccadic [5] and simple reaching movements [6-8], thus improving motor performance in terms of both speed and accuracy. However, most previous research has been conducted in healthy, young adults, and therefore the application of reward in terms of motor performance in older adults is relatively understudied.

There are multiple theories as to the mechanism by which reward improves motor performance. One such theory is that reward enhances the velocity of individual movements, as seen in simple, discrete reaching tasks $[6,7]$. This increase in velocity is associated with an increase in co-contraction of the muscles, resulting in stiffness of the effector, reducing movement noise, thus maintaining accuracy at higher speeds [9]. Expanding on this, Codol, Holland [7] found that reward enhanced multiple errorreduction mechanisms, leading to not only improved feedback control but also decreased motor noise near the target due to an increase in stiffness. Due to this association, the present study used changes in maximum velocity as an insight into increases in stiffness. While attractively simple, it should be noted that this increase in stiffness is energetically inefficient and metabolically taxing [9]. Further to 
bioRxiv preprint doi: https://doi. org/10.1101/2021.09.27.461920; this version posted September 27, 2021. The copyright holder for this preprint (which was not certified by peer review) is the author/funder, who has granted bioRxiv a license to display the preprint in perpetuity. It is made available under aCC-BY-NC-ND 4.0 International license.

this, performance gains disappear when reward is removed [5-7] suggesting that sustained reward is required to negate the energetic requirements of invigorated movement. This raises questions as to whether older adults, on whom everyday activities such as walking are more metabolically demanding [10], would improve their motor performance through such a metabolically demanding mechanism.

Another mechanism of interest for motor performance improvement is coarticulation. Essential to understanding sequential actions, coarticulation refers to the blending together of sub-movements into continuous action, executed with increased speed and smoothness [3, 11, 12]. Critically, and conversely to increases in maximum velocity, improvements in coarticulation are associated with increased energetic efficiency of a movement as straight trajectories of single movements are gradually replaced with longer curved ones, increasing smoothness [3]. Coarticulation is not an innate process, rather it is learned [13] and can take weeks to achieve [3, 11]. Sporn, Chen and Galea [14] propose that reward facilitates learning of coarticulation and showed that with reward this typically long process is accelerated. Additionally, they propose that unlike increases in maximum velocity, this process becomes reward-independent once learned, with improvements in energetic efficiency being crucial to maintaining performance gains. However, this work was only conducted in young participants, so it is unclear whether there are any age-related changes in the brain which lead participants to utilise different mechanisms for motor improvement in the presence of reward, or whether these differences are simply a product of the task (discrete movements using increases in maximum velocity vs sequential movements using coarticulation).

The present study was designed to investigate whether older adults use reward to improve their motor performance in the same way as has been extensively shown in younger adults. Younger and older adults took part in an online sequential reaching task where they either received reward based on their movement time or no reward. Through comparison of various measures of motor performance (movement time, maximum velocity and coarticulation), it is possible to assess whether older adults respond to reward in the same way as younger adults. Further, the current study aims to 
investigate the underlying mechanism associated with improvements in motor performance and whether this shows age-related effects.

\section{Method}

\section{Participants}

100 participants took part in the study across two groups: young adults ( $N=50,27$ males) and older adults ( $N=50,21$ males, 1 unknown). The young adult group's ages ranged from $18-23$ with a mean age of 20.1 years $(S D=1.43)$. The older adult group's ages ranged from $65-79$, with a mean age of 69.8 years $(S D=3.92)$. Participants were recruited via Prolific (www. prolific.ac) to take part in an online sequential reaching task. All participants had normal or corrected-to-normal vision and no motor or psychological impairments. Participation in the study was voluntary and participants were compensated $\mathrm{f7.50/hour,} \mathrm{in} \mathrm{addition} \mathrm{to} \mathrm{performance-based} \mathrm{monetary} \mathrm{reward.} \mathrm{All} \mathrm{participants} \mathrm{gave}$ written informed consent before partaking in the study and ethical approval was obtained through the University of Birmingham's Departmental Ethics Board.

\section{Materials}

The online task was coded in Java and hosted on the Gorilla Experiment Builder server [15]. Participants were recruited via Prolific (www.prolific.ac) and could use any smartphone touchscreen device. Data was downloaded directly from the Gorilla server. Code for task is available here; https://osf.io/9qk2n/

\section{Design}

Experimental Design

The current study employed a 2 (age: young (18-23 years) vs old (65-79 years)) x 2 (feedback: no reward vs reward) between-subjects design. Participants were randomly assigned to the reward 
bioRxiv preprint doi: https://doi org/10.1101/2021.09.27.461920; this version posted September 27, 2021. The copyright holder for this preprint (which was not certified by peer review) is the author/funder, who has granted bioRxiv a license to display the preprint in perpetuity. It is made available under aCC-BY-NC-ND 4.0 International license.

condition at the beginning of the experiment, ensuring equal participants in each group, resulting in four groups: young reward (YR), old reward (OR), young no-reward (YNR), and old no-reward (ONR).

\section{Task Design}

Four circular targets were arranged around a central 'via target' (Figure 2b). Based on pilot data using the novel online task, each target encompassed $12.5 \%$ of participants' screen to allow for coarticulation [16]. As participants' phone sizes varied, the $\mathrm{x}$ and $\mathrm{y}$ position of each target was calculated as a percentage of the screen from the top and left of the viewport to ensure consistency (Figure 2c). Targets 2 and 3 were positioned with an obtuse angle of 126 degrees between them and the via target to ensure coarticulation was possible [3].

A.

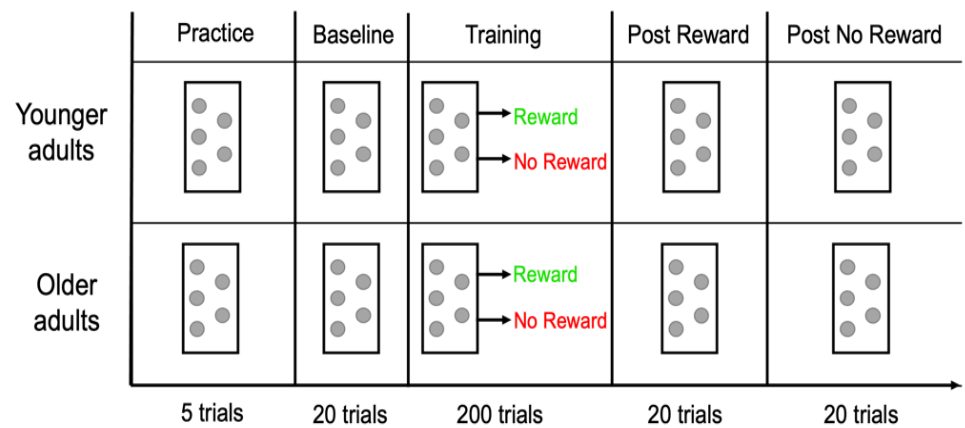

B.

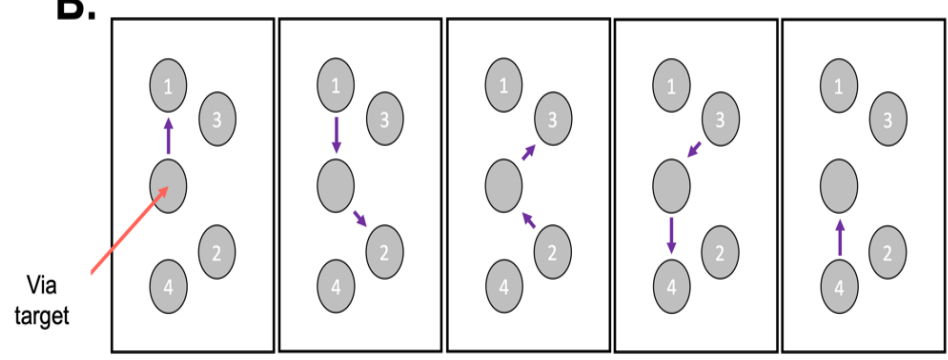

C.

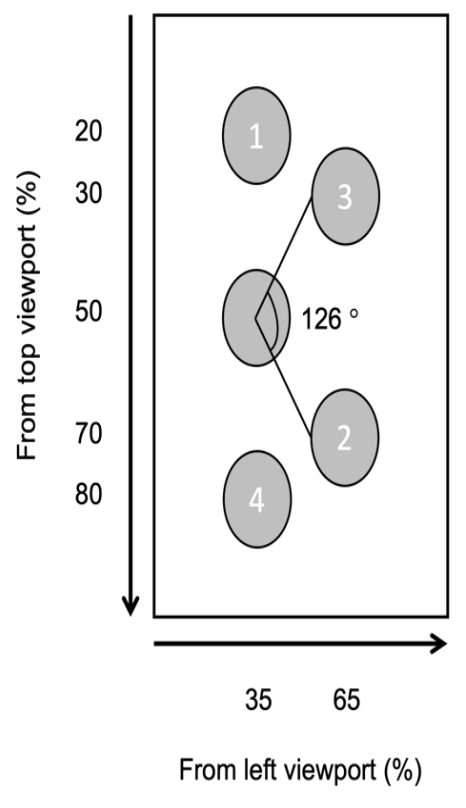

Figure 1: Experimental setup. a) Study design. Participants will be trained on the sequence during practice trials and then asked to perform 20 baseline trials with no reward. Participants will be randomly allocated to the reward or no reward group and complete 200 trials followed by two blocks of 20 post assessment trials: post-reward and post-noreward. b) 8 sequential movements to be performed in each trial starting from the central 'via target'. c) Target positions as percentages from top/left of viewport.

\section{Procedure}


bioRxiv preprint doi: https://doi org/10.1101/2021.09.27.461920; this version posted September 27, 2021. The copyright holder for this preprint (which was not certified by peer review) is the author/funder, who has granted bioRxiv a license to display the preprint in perpetuity. It is made available under aCC-BY-NC-ND 4.0 International license.

The experiment consisted of 5 blocks: learning, baseline, training, post-reward and post-no-reward, replicating that of Sporn et al. [14](Figure 2a). Participants were instructed to hold their device with their non-dominant hand and complete trials as fast and accurately as possible with the index finger of their dominant hand.

\section{Learning}

An initial learning phase was included, preceding the main experiment, to ensure participants had memorised the movement sequence. Participants were required to press the via target for $1.5 \mathrm{~s}$ to cue the start of a trial. During a trial, participants were asked to slide their finger from the central via target towards four surrounding targets which were simultaneously presented on the screen. The targets were numbered in order of required execution and the finger moved back to the central via target after each movement before moving onto the next target. This resulted in eight continuous reaching movements per trial (Figure $2 \mathrm{~b}$ ). Participants had to complete 5 trials successfully before proceeding to the next block to ensure memorisation of the sequence, enabling subsequent performance gains to be attributed to better execution rather than memory. Trials in this block were not rewarded.

\section{Baseline}

This block consisted of 20 trials to assess pre-training differences across groups. Trials were performed in the same way but without the numbered cues. Trials were not rewarded but participants were asked to complete each trial as fast and accurately as possible. No performance-related feedback was given.

Training

This block consisted of 200 trials performed in the same way as the baseline block. Participants were randomly assigned to either the reward or no-reward condition. The reward group were told they could gain reward $(0-5 p)$ based on their movement time, with faster performances resulting in more reward. After each trial, participants received performance-related feedback in the form of amount 
of money earned. The no-reward group were told they would not be rewarded but to perform each trial as fast and accurately as possible. No performance-related feedback was provided to the noreward group (Figure 3).

\section{Post-Assessments}

Participants were asked to complete two post assessments: post-reward where all participants were rewarded; and post-no-reward where no participants were rewarded. Each block consisted of 20 trials performed in the same way as training trials.

\section{Reward Feedback Calculation}

Additional reward value was determined using a closed-loop design comparing participant's MT to their performance on the previous 20 trials. These MTs were sorted from fastest to slowest and the rank of the current MT in the array was used to allocate reward (Table 1), encouraging participants to improve performance throughout.

Table 1. Ranks of participants' movement time and corresponding reward

\begin{tabular}{cc}
\hline Rank & Reward \\
\hline$>=90 \%$ & $5 p$ \\
$<90 \%$ and $>=80 \%$ & $4 p$ \\
$<80 \%$ and $>=60 \%$ & $3 p$ \\
$<60 \%$ and $>=40 \%$ & $2 p$ \\
$<40 \%$ and $>=20 \%$ & $1 p$ \\
$<20 \%$ & $0 p$ \\
\hline
\end{tabular}

Note. As participants start a new block, MT was compared to the last 20 trials of the previous block 


\section{Training Trials}

\section{Reward}

Over the next 200 trials you will be able to earn additional money (reward) through your performance. On each trial, you will be able to earn between $0-5 p$ based on your movement time. However, remember for a trial to be valid you have to hit all targets accurately and in the correct order

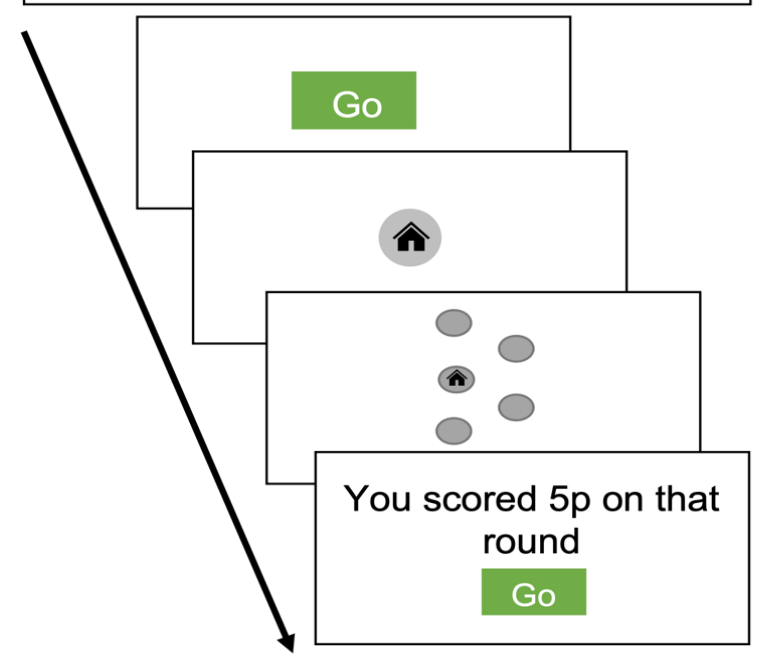

No Reward

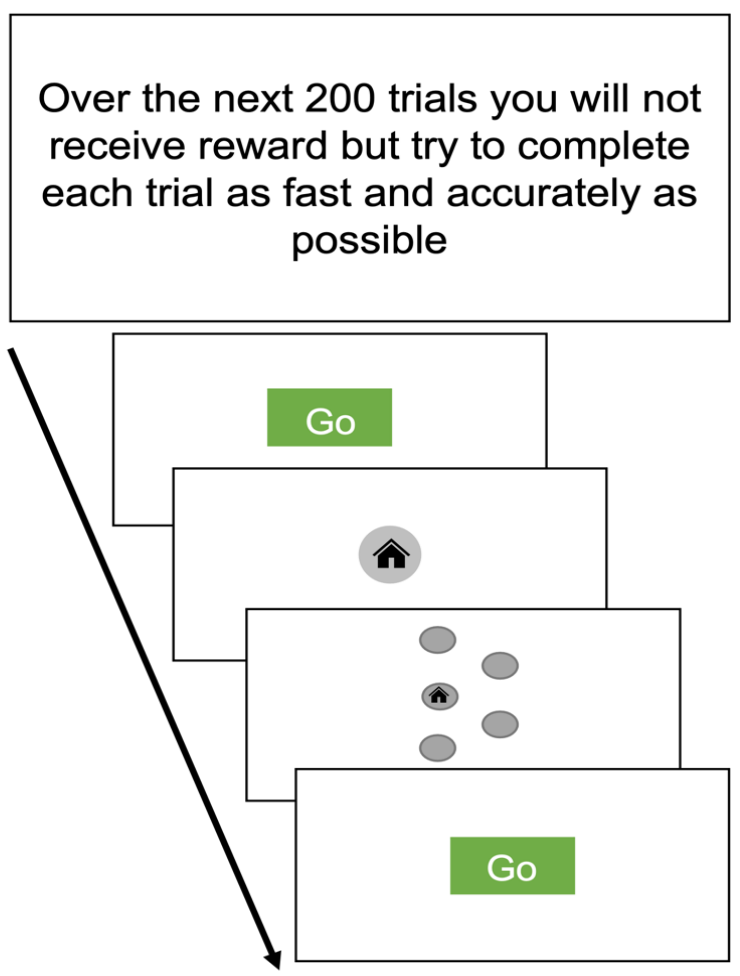

Figure 2: Training trials. Experimental setup of reward and no reward training trials showing the order of instruction and cues that will be used. After each reward trial, participants will be informed of how much reward they have earned on the trial. This will range from $0-5 p$.

\section{Data Analysis}

Movement time (MT)

Movement time was calculated as the time between exiting the start target and entering the final target of each trial.

Maximum velocity (MV)

Maximum velocity was calculated using the derivative of positional data to create velocity profiles for each trial. Velocity profiles were smoothed with a Gaussian kernel $(\sigma=1)$ and divided into 8 segments, to represent individual movements towards targets, using target entry and exit data (Figure 4a). The maximum velocity for each movement was found using the Matlab function, max and the mean of these 8 values was calculated to give one value for MV per trial. 
Coarticulation Index (Cl)

Coarticulation can be observed as the eight distinct velocity profiles for each individual movement

(Figure 4a) are gradually replaced by five velocity peaks, as adjacent movements merge together

(Figure 4b). This study uses $\mathrm{Cl}$ as a measure of the extent sequential movements blend in each trial.

$\mathrm{Cl}$ was calculated using equation 1 :

Coarticulation Index $=1-\frac{\frac{\left(V_{\max 1}+V_{\max 2}\right)}{2}-V_{\min }}{\frac{\left(V_{\max 1}+V_{\max 2}\right)}{2}} \quad$ Equation 1

where $V_{\max 1}$ and $V_{\max 2}$ are the maximum velocities of the out-centre and centre-out movements

respectively (Figure $4 \mathrm{~d}$ ) and $\mathrm{V}_{\min }$ represents the minimum velocity between these points. The closer

these values, the greater the coarticulation (Figure 4c). It is hypothesised that coarticulation will

occur between movements which result in an obtuse angle (target-centre-out movements; [3])

hence only movements 2-7 (Figure 4a) were included in this analysis. This results in $\mathrm{Cl}$ scores ranging

from 0-3 per trial, with a score of 3 indicating three fully coarticulated movements. 
A.

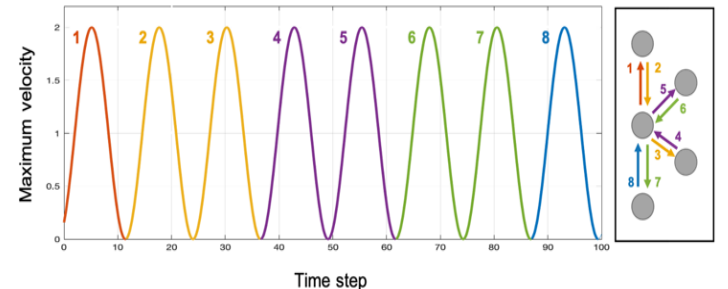

C.

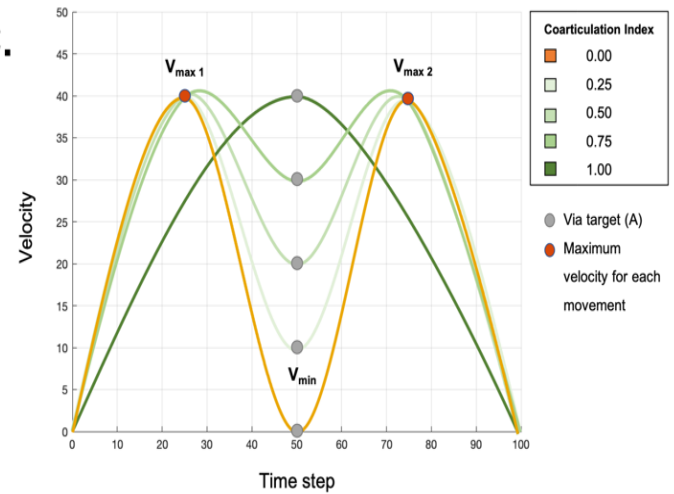

B.

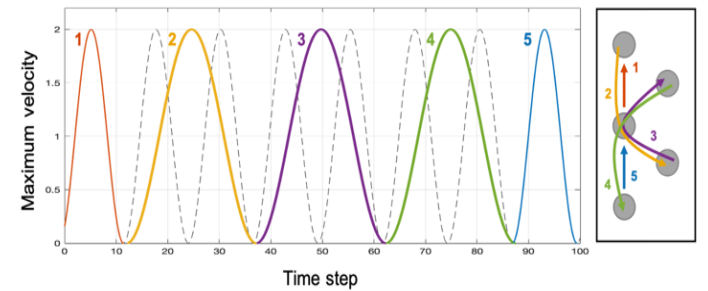

D.
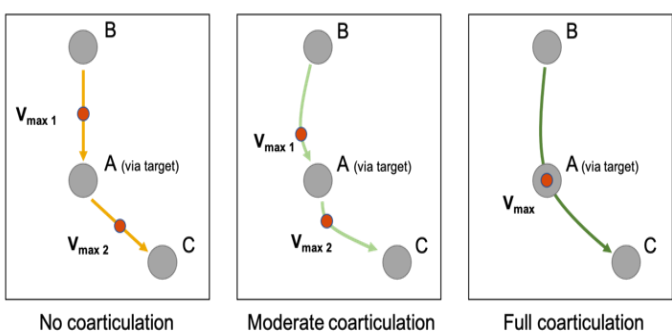

Figure 4: Coarticulation. a) Schematic velocity profiles showing 8 individual movements. b) Schematic velocity profiles showing the difference between individual and coarticulated movements in one trial based on predictions from Sosnik et al. (2007). c) Different levels of coarticulation between two movements. d) Movement trajectories for two individual movements (no coarticulation), two curved movements (moderate coarticulation), and one fully blended movement (full coarticulation).

Error

Participants will be cued to repeat a trial if: they miss the target; hit the targets in the wrong order;

lift their finger before the trial is complete; or move out of the start button too early. Error will be operationalised as the percentage of MT trials with a result of NaN.

\section{Statistical Analyses}

All measures stated were calculated from the raw data. Outliers (values > mean \pm 10 SD) were removed. 11 participants $(9.4 \%)$ had errors $>20 \%$ and so were removed and their data replaced. A further 6 participants (5.1\%) were removed and replaced due to measurement error resulting in too many trials. 2 (age: old vs young) x 2 (reward: reward vs no reward) ANOVAs were conducted to analyse differences in performance at baseline for each measure. Measures with significant main effects for age were baseline corrected by subtracting the mean at baseline for each participant from each subsequent trial. To analyse the effect of timepoint, mean values for the first and last 20 trials in the training block were calculated as early and late training respectively. One-sample Kolmogorov- 
bioRxiv preprint doi: https://doi org/10.1101/2021.09.27.461920; this version posted September 27, 2021. The copyright holder for this preprint (which was not certified by peer review) is the author/funder, who has granted bioRxiv a license to display the preprint in perpetuity. It is made available under aCC-BY-NC-ND 4.0 International license.

Smirnov tests and subsequent inspection of histograms revealed that all measures were non-normally distributed. As there is a lack of non-parametric alternative and ANOVAs are fairly robust to violations of normality, it was decided that three-way mixed ANOVAs would be used to examine each measure during training and post-assessments. For training, timepoint (early vs late training) is the withinsubjects factor. For post-assessments, phase (post-reward vs post no-reward) is the within-subjects factor. Both ANOVAs use age (young vs older adults) and feedback (reward vs no-reward) as the between-subjects factors. Significant interactions and main effects were followed up with MannWhitney $\mathrm{U}$ or Wilcoxon tests accounting for multiple comparisons through Bonferroni correction. Spearman's Rank correlations were performed between measures to assess the strength of the relationship in each group and gain an insight into the mechanisms employed.

\section{Results}

\section{Screen Size}

As the task was online, phone sizes were not controlled across participants, therefore it was necessary to compare phone screen area across groups to ensure this was not a factor during the experiment. A 2 (age: old vs young) $\times 2$ (reward: reward vs no-reward) ANOVA was conducted. There was no statistically significant interaction between the effects of age and reward on screen area $(F(1,96)=$ $.220, p=.640)$ nor was there a statistically significant main effect of age $(F(1,96)=3.356, p=.070)$ or reward $(F(1,96)=.464, p=.497)$ so this did not need to be accounted for during statistical analysis.

\section{Reward Invigorates Movement Time in Both Young and Old Adults}

During baseline there was a significant main effect of age on MT, with older adults producing longer MTs compared to young $\left(F(1,96)=35.7, p<.001, \eta^{2}{ }_{p}=.271 ;\right.$ Table 2$)$. The data was therefore baseline corrected (see 'statistical analyses'). Our results highlight that reward decreases MT in both old and young adults (Figure 5a). Specifically, there was a significant decrease in MT over the course of training for all groups (mixed ANOVA; main effect for timepoint (early vs late), $F(1,96)=57.4, p<.001, \eta^{2}{ }_{p}=$ 
bioRxiv preprint doi: https://doi. org/10.1101/2021.09.27.461920; this version posted September 27, 2021. The copyright holder for this preprint (which was not certified by peer review) is the author/funder, who has granted bioRxiv a license to display the preprint in perpetuity. It is made available under aCC-BY-NC-ND 4.0 International license.

.374 ; Figure 5b). Interestingly, in comparison to younger participants, older adults performed faster relative to baseline (main effect for age; $F(1,96)=4.59, p=.035, \eta_{p}^{2}=.046$ ). Similarly, rewarded groups produced significantly faster MTs across training than the non-rewarded groups (significant main effect of reward, $F(1,96)=14.3, p<.001, \eta_{p}^{2}=.130$; Table 3$)$. However, there no significant interaction between age and reward.

Table 2. Movement time (ms). Means and standard deviations for each group at baseline

\begin{tabular}{ccc}
\hline & $M$ & SD \\
\hline Old Reward & 3774 & 1348 \\
Old No Reward & 3592 & 1214 \\
Young Reward & 2421 & 1032 \\
Young No Reward & 2135 & 1083 \\
\hline
\end{tabular}

A.

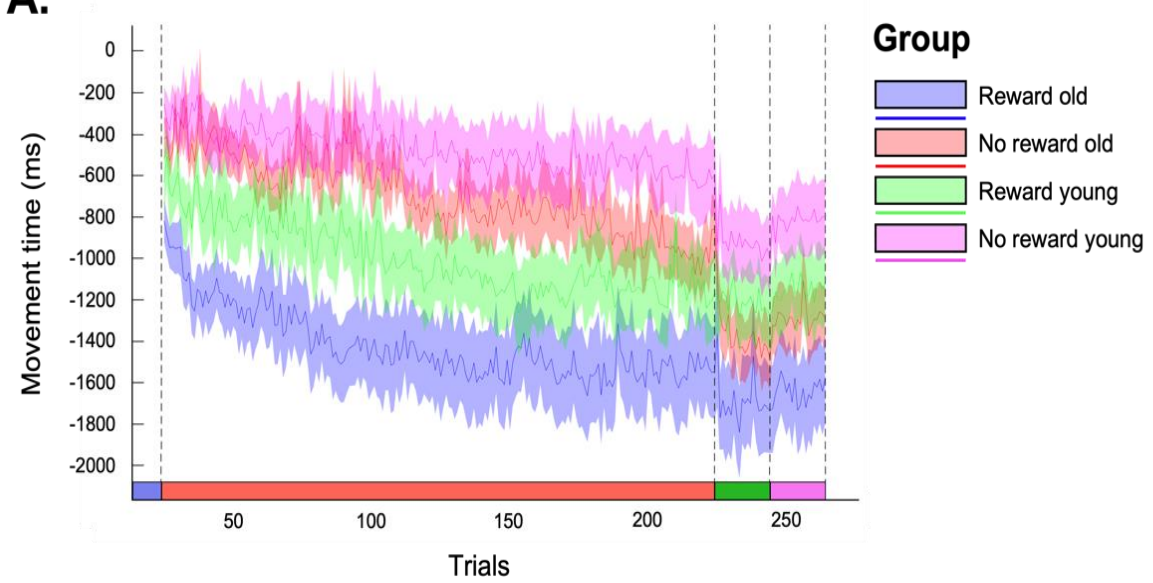

\section{Experimental Phase}

B.

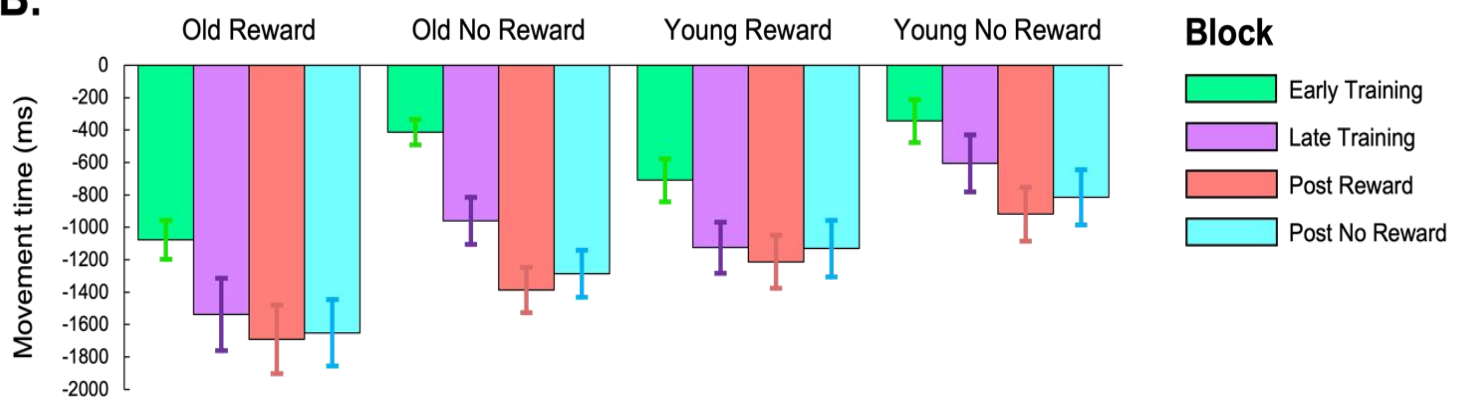

Figure 5: MT. a) Trial by trial changes in MT, baseline corrected and averaged over participants for all four groups. Shaded area represents standard error of the mean. b) Mean MT values for each group comparing MT performance during early training, late training, post reward and post no reward blocks. Error bars represent standard error of the mean. 
Table 3. Movement time (ms). Marginal means and standard error for each level of each factor

\begin{tabular}{llll}
\hline Factor & & $M$ & SE \\
\hline Timepoint & Early & -636 & 75.5 \\
& Late & -1056 & 75.5 \\
Age & Old & -997 & 99.3 \\
& Young & -696 & 99.3 \\
Reward & Reward & -1112 & 99.3 \\
& No Reward & -581 & 99.3 \\
\hline
\end{tabular}

Older Adults Retain MT Improvements After Reward is Removed

A mixed ANOVA with age (old vs young) and reward (reward vs no-reward) as between-subjects factors and phase (post-R vs post-NR) as a within-subjects factor revealed a significant main effect for phase on MT, with MTs being significantly faster in the post-R block compared to the post-NR block (mixed ANOVA; main effect for phase; $F(1,96)=13.0, p<.001, \eta^{2}{ }_{p}=.119$; Figure $5 b$ ). There was also a significant main effect of age $\left(F(1,96)=7.89, p=.006, \eta^{2}{ }_{p}=.076\right)$ with older participants having faster MTs than young participants, relative to baseline (Table 4). To assess whether individual groups maintained improvements once reward was removed, exploratory analysis was performed. There was a significant difference between late training and post-R blocks for all groups (Table 5) indicating that reward invigorated performance during post- $R$ trials in all groups, including those who had received reward throughout (Figure 5b). However, Wilcoxon Signed-Rank tests between Post-R and Post-NR blocks for each group only yielded significant results for the YNR group. This indicates that rewardbased improvements in MT in older participants were maintained after the removal of reward, including the ONR group who had only experienced reward for 20 trials. Contrastingly, the improvements for young participants were only maintained in the YR group, with the YNR group's improvement remaining transient (Table 6).

Table 4. Movement time (ms). Marginal means and standard error for each level of each factor

\begin{tabular}{llll}
\hline Factor & & $M$ & SE \\
\hline Phase & Post-Reward & -1302 & 86.9 \\
& Post-No Reward & -1221 & 86.9 \\
Age & Old & -1503 & 121.8 \\
\hline
\end{tabular}




\begin{tabular}{llll}
\hline \multirow{3}{*}{ Reward } & Young & -1020 & 121.8 \\
& Reward & -1421 & 121.8 \\
& No Reward & -1102 & 121.8 \\
\hline
\end{tabular}

Table 5. Movement time. Results of Wilcoxon Signed-Rank tests for each group between late training and post-R blocks

\begin{tabular}{lll}
\hline & $\mathrm{Z}$ & $p$ \\
\hline Old Reward & -2.87 & $.004^{*}$ \\
Old No Reward & -4.05 & $<.001^{*}$ \\
Young Reward & -2.62 & $.009^{*}$ \\
Young No Reward & -4.37 & $<.001^{*}$ \\
\hline
\end{tabular}

* indicates a significant result at the Bonferroni corrected level of 0.0125

Table 6. Movement time. Results of Wilcoxon Signed-Rank tests for each group between post- $R$ and post-NR blocks

\begin{tabular}{lll}
\hline & $\mathrm{Z}$ & $p$ \\
\hline Old Reward & -.928 & .353 \\
Old No Reward & -1.44 & .150 \\
Young Reward & -2.14 & .032 \\
Young No Reward & -3.54 & $<.001^{*}$ \\
\hline
\end{tabular}

* indicates a significant result at the Bonferroni corrected level of 0.0125

Reward Invigorates MV in Both Age Groups but Only Improves Rate in Young Adults

During baseline there was a significant main effect of age on MV, with older adults performing at lower MVs compared to young, $F(1,96)=49.0, p<.001, \eta_{p}^{2}=.338$ (Table 7). Therefore, the data was baseline corrected in the same way as for MT. Our results highlight that MV is invigorated by reward in both age populations in early training, however, reward only invigorates improvement over training in young participants (Figure 6a).

Table 7. Maximum velocity $(\mathrm{cm} / \mathrm{s})$. Means and standard deviation for each group at baseline

\begin{tabular}{lll}
\hline & $M$ & SD \\
\hline Old Reward & 16.6 & 7.53 \\
Old No Reward & 17.7 & 5.19 \\
\hline
\end{tabular}




\begin{tabular}{lll}
\hline Young Reward & 25.0 & 5.56 \\
Young No Reward & 26.7 & 6.21 \\
\hline
\end{tabular}

\section{A.}
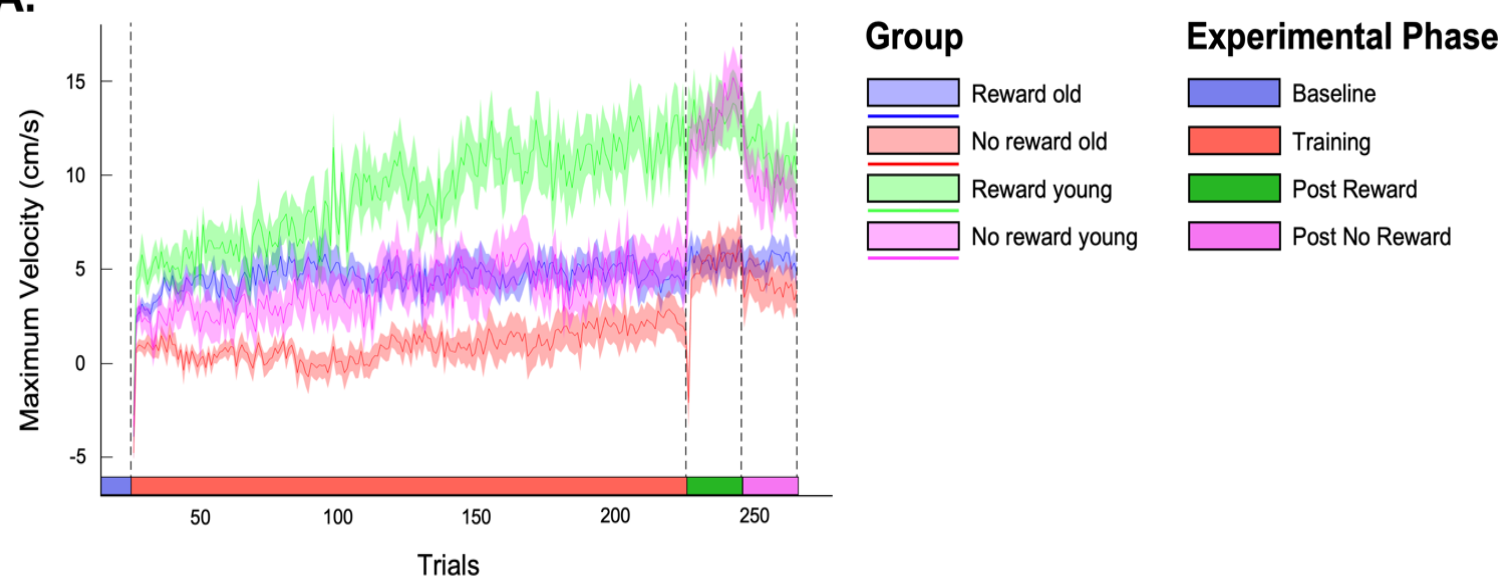

B.

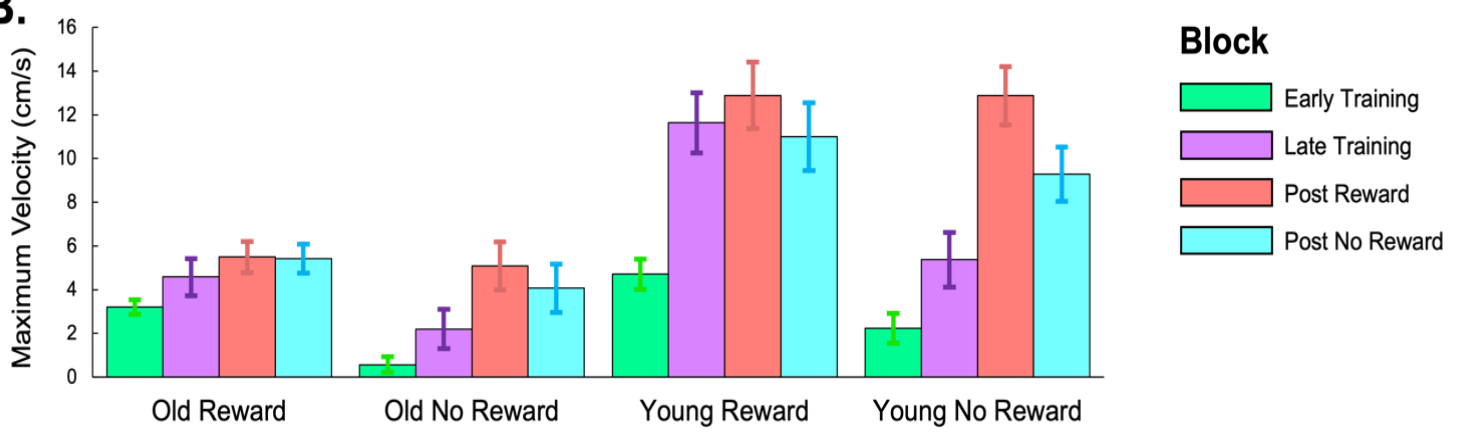

Figure 6: MV. a) Trial by trial changes in MV, baseline corrected and averaged over participants for all four groups. Shaded area represents standard error of the mean. b) Mean MV values for each group comparing MV performance during early training, late training, post reward and post no reward blocks. Error bars represent standard error of the mean.

Reward invigorated MV in early training for both age groups (OR vs ONR: $U=81, p<.001$; YR vs YNR: $U=181, p=.011$ ). To assess how reward and age affected MV across training, a three-way mixed ANOVA was conducted. A significant three-way interaction was found (mixed ANOVA; timepoint $x$ age $\mathrm{x}$ reward; interaction; $\left.F(1,96)=4.07, p=.047, \eta^{2}{ }_{p}=.041\right)$ indicating that $\mathrm{MV}$ increases across training are contingent on group membership (Figure 6a). A two-way ANOVA was therefore conducted to examine the effects of age and reward on the difference in MV between early and late training. There was a statistically significant interaction between age and reward $\left(F(1,96)=4.07, p=.047, \eta^{2}{ }_{p}=.041\right)$ therefore simple main effects analysis for reward and age were performed. Multiple comparisons were accounted for using a Bonferroni-adjusted $p$-value of .025 . There was a statistically significant simple main effect of reward on $\mathrm{MV}$ across training for young participants $\left(F(1,96)=7.10, p=.009, \eta^{2}\right.$ p 
bioRxiv preprint doi: https://doi org/10.1101/2021.0927 461920; this version posted September $27,2021$. The copyright holder for this preprint (which was not certified by peer review) is the author/funder, who has granted bioRxiv a license to display the preprint in perpetuity. It is made available under aCC-BY-NC-ND 4.0 International license.

$=.069$ ), with the rewarded group improving more over the course of training (Table 8). There was no significant main effect of reward in older participants $\left(F(1,96)=.035, p=.852, \eta^{2}{ }_{p}=.000\right)$. This suggests that reward does not affect the rate at which MV increases over training in older adults but does in younger adults. There was also a statistically significant main effect for age on MV across training in the rewarded group $\left(F(1,96)=15.3, p<.001, \eta^{2}{ }_{p}=.137\right)$ with young participants improving more over the course of training (Table 8). There was no significant simple main effect of age in the non-rewarded group $\left(F(1,96)=1.10, p=.297, \eta_{p}^{2}=.011\right)$. This suggests that age only affects the rate at which MV increases over training in the presence of reward.

Table 8. Maximum Velocity $(\mathrm{cm} / \mathrm{s})$. Marginal means and standard error for each group

\begin{tabular}{llll}
\hline Group & & $M$ & SE \\
\hline Old & Reward & 1.38 & 1.01 \\
& No-Reward & 1.64 & 1.01 \\
Young & Reward & 6.93 & 1.01 \\
& No-Reward & 3.13 & 1.01 \\
\hline
\end{tabular}

Older Adults Retain Increases in MV After the Removal of Reward

Post-assessments revealed a significant main effect for phase (mixed ANOVA; main effect for phase; $F(1,96)=18.25, p<.001, \eta_{p}^{2}=.160$; Figure $\left.6 b\right)$ with $M V$ in the post- $\mathrm{R}$ block being significantly higher than in the post-NR block. There was also a significant main effect for age (mixed ANOVA; main effect for age; $\left.F(1,96)=33.0, p<.001, \eta_{p}^{2}=.256\right)$ and a significant interaction between phase and age (mixed ANOVA; phase $\mathrm{x}$ age; interaction; $F(1,96)=8.08, p=.005, \eta^{2}{ }_{\mathrm{p}}=.078$; Table 9).

Table 9. Maximum velocity $(\mathrm{cm} / \mathrm{s})$. Marginal means and standard error for each level of each factor

\begin{tabular}{llll}
\hline Factor & & $M$ & SE \\
\hline Phase & Post-R & 9.09 & .597 \\
& Post-NR & 7.45 & .597 \\
Age & Old & 5.02 & .800 \\
& Young & 11.5 & .800 \\
Reward & Reward & 8.70 & .800 \\
& No Reward & 7.83 & .800 \\
\hline
\end{tabular}


It was shown that there was a significant difference between late training and post- $\mathrm{R}$ blocks for all groups except YR (Table 10) indicating that reward invigorated MV during post-R trials in both older adult groups and the YNR group but did not invigorate the YR group. Also, Wilcoxon Signed-Rank tests (Table 11) between Post-R and Post-NR blocks for each group only yielded significant results for the young no-reward group. This suggests that while both old and young participants in the no-reward groups can instantaneously increase MV during post- $R$, the 'on-off' effect across post-assessments is only seen in young participants. Old no-reward participants maintained the effects of reward after only 20 post-R trials, whereas MV decreased for YNR participants when reward was removed. MannWhitney $\mathrm{U}$ tests comparing reward vs no-reward in the post- $\mathrm{R}$ block for both age groups yielded nonsignificant results (OR vs ONR: $U=271, p=.421$; YR vs YNR: $U=309, p=.946$ ) showing that when reward is introduced, MV is instantly invigorated to a similar level as groups who have received reward throughout training.

Table 10. Maximum Velocity. Results of Wilcoxon Signed-Rank tests for each group between late training and post- $R$ blocks

\begin{tabular}{lll}
\hline & $Z$ & $p$ \\
\hline Old Reward & -3.14 & $.002^{*}$ \\
Old No Reward & -4.24 & $<.001^{*}$ \\
Young Reward & -2.01 & .045 \\
Young No Reward & -4.37 & $<.001^{*}$ \\
\hline
\end{tabular}

* indicates a significant result at the Bonferroni corrected level of .0125

Table 11. Maximum velocity. Results of Wilcoxon Signed-Rank tests for each group between post- $R$ and post-NR blocks

\begin{tabular}{lll}
\hline & $Z$ & $p$ \\
\hline Old Reward & -.605 & .545 \\
Old No Reward & -1.74 & .083 \\
Young Reward & -1.36 & .174 \\
Young No Reward & -3.38 & $<.001^{*}$ \\
\hline
\end{tabular}


* indicates a significant result at the Bonferroni corrected level of 0.0125

\section{Coarticulation Increases Across Training Were Not Age or Reward Dependent}

During baseline there was a significant main effect of age on $\mathrm{Cl}$, with older adults producing lower $\mathrm{Cls}$ compared to young $\left(F(1,96)=16.9, p<.001, \eta_{p}^{2}=.149 ;\right.$ Table 12$)$. Therefore, the data was baseline corrected. There was a significant effect of timepoint upon $\mathrm{Cl}, F(1,96)=86.7, p<.001, \eta^{2}{ }_{p}=.475$ indicating that participants learned to coarticulate more across training (Figure 7a). However, there were no further significant main effects or interactions, indicating that these increases were independent of age or reward manipulation. Post-assessments also revealed no significant main effect of phase (mixed ANOVA; main effect for phase, $F(1,96)=1.41, p=.238, \eta^{2}{ }_{p}=.014$ ) indicating the stability of $\mathrm{Cl}$ in each group (Figure $7 \mathrm{~b}$ ).

Table 12. Coarticulation index. Means and standard deviation for each group at baseline

\begin{tabular}{lll}
\hline & $M$ & SD \\
\hline Old Reward & .253 & .182 \\
Old No Reward & .209 & .214 \\
Young Reward & .493 & .518 \\
Young No Reward & .707 & .677 \\
\hline
\end{tabular}



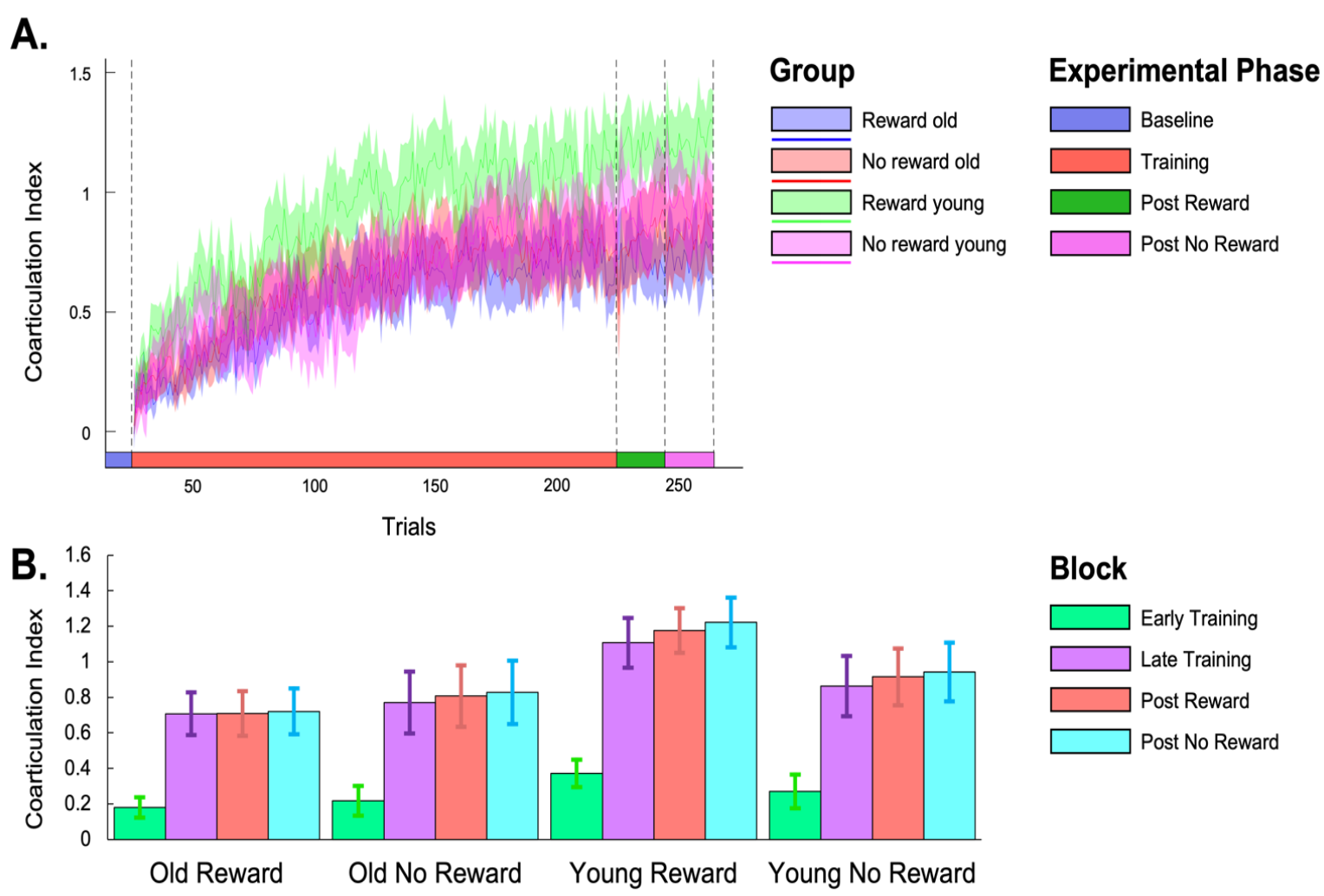

Figure 7: $\mathrm{Cl}$. a) Trial by trial changes in $\mathrm{Cl}$, baseline corrected and averaged over participants for all four groups. Shaded area represents standard error of the mean. b) Mean $\mathrm{Cl}$ values for each group comparing $\mathrm{Cl}$ performance during early training, late training, post reward and post no reward blocks. Error bars represent standard error of the mean.

\section{Old and Young Adults Improve MT Using Different Mechanisms}

MT difference across training was correlated with $\mathrm{MV}$ and $\mathrm{Cl}$ difference across training (post-pre) to gain a greater understanding of the mechanisms by which performance improves at a participant level. There was a significant correlation between MT and MV for all groups, (OR: $r_{s}=-.745, p<.001$; ONR: $r_{s}=-.471, p=.018 ;$ YR: $r_{s}=-.716, p<.001 ;$ YNR: $r_{s}=-.555, p=.004$; Figure 8a). However, correlations between $\mathrm{MT}$ and $\mathrm{Cl}$ were only significant in young adult groups, (OR: $r_{s}=-.225, p=.280$; ONR: $r_{s}=-$ $.142, p=.500 ;$ YR: $r_{s}=-.817, p<.001 ;$ YNR: $r_{s}=-.598, p=.002$; Figure $\left.8 b\right)$. This indicates that improvements in MT in older adults are associated with improvements in MV whilst young adults' MT is associated with improvements in both $\mathrm{MV}$ and $\mathrm{Cl}$. 
A.
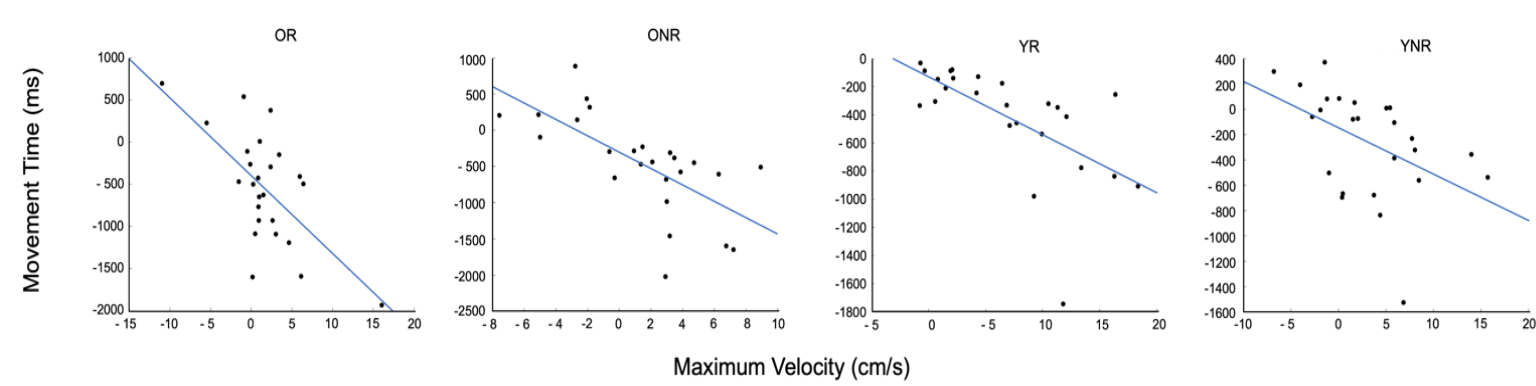

B.
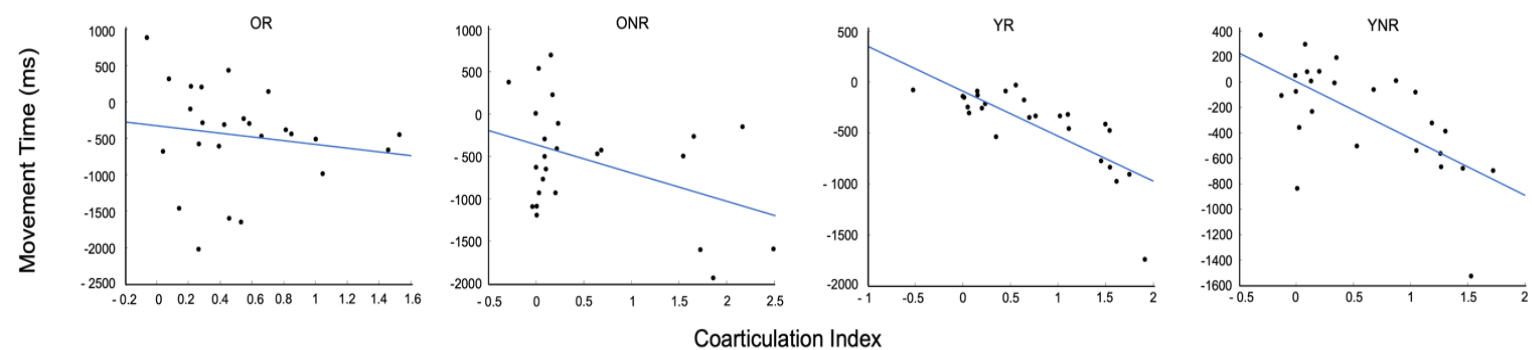

Figure 8: Correlations. Scatterplots for each group displaying the relationship between the difference in MT across training and $\mathbf{a}$ ) the difference in $\mathrm{MV}$ across training and $\mathbf{b}$ ) the difference in $\mathrm{Cl}$ across training with a linear line fitted to the data.

\section{Discussion}

Reward has been used to improve motor performance in young adults successfully, however its application throughout the lifespan remains relatively understudied. We investigated whether reward could be used to improve motor performance on a sequential reaching task in older adults, and whether mechanisms underlying this improvement differed by age group. This was assessed via decreases in movement time (MT) across training and assessments of two mechanisms: increases in maximum velocity (MV) and coarticulation index $(\mathrm{Cl})$. Here we provide evidence that reward can improve performance of sequential reaching in both younger and older adults. Our results also indicate that different mechanisms may be used by different age groups; however, the intricacies of these mechanisms remain unclear.

Consistent with previous research showing age-related differences in motor performance across the lifespan [17-19], and our hypothesis, older adults had longer MTs overall, meaning they performed more slowly than their young counterparts. However, once this overall effect was corrected for, we 
bioRxiv preprint doi: https://doi. org/10.1101/2021.09.27.461920; this version posted September 27, 2021. The copyright holder for this preprint (which was not certified by peer review) is the author/funder, who has granted bioRxiv a license to display the preprint in perpetuity. It is made available under aCC-BY-NC-ND 4.0 International license.

found that reward invigorated MT in both age groups, leading to faster performances in rewarded groups. Our results lend further evidence to the literature which argues that reward can be used as a tool for motor performance improvement in reaching movements [5-8] and replicates this finding for the first time, to the best of our knowledge, during sequential reaching in older adults.

Interestingly, we found no interaction between age and reward on $\mathrm{MT}$, suggesting that there were no differences in sensitivity to reward across age groups. This finding is concordant with Huang et al. [20] who suggested preservation of reward-based learning in reaching adaptation during healthy aging; finding equivalently faster learning rates in both ages with rewarding feedback. However, it is at odds with evidence from decision paradigms suggesting older adults are less sensitive to reward [21, 22]. This suggests that age-related differences in motivational modulation are dependent on task characteristics, with motivational modulation of motor performance remaining stable across the lifespan. It is important to note that in both this study and Huang et al. [20], the task was relatively simple. There is evidence to suggest that performance differences increase between older and younger adults as task difficulty increases [23], thus, it is feasible that this relationship may also apply to reward processing. Therefore, the present study may not have been complex enough to disentangle any age-related reward-sensitivity differences. Further to this, young adults performed significantly faster than older adults at baseline, and we speculate that they experienced a ceiling phenomenon where their performance was close to maximal, thus leaving little room for improvement.

We demonstrated that reward invigorated $\mathrm{MV}$ in both age groups, replicating reward-based invigoration of discrete reaching movements in an aged population [6, 7]. However, an interesting interaction was found between age and reward indicating that while reward invigorated $\mathrm{MV}$ in both age groups, reward only increased the rate of improvement in young participants. Older adults improved their MV instantaneously and maintained this effect, even after the removal of reward. From this we propose that to maximise performance gains in older adults, intermittent reward could be trialled. 
bioRxiv preprint doi: https://doi.org/10.1101/2021.09.27.461920; this version posted September 27, 2021. The copyright holder for this preprint (which was not certified by peer review) is the author/funder, who has granted bioRxiv a license to display the preprint in perpetuity. It is made available under aCC-BY-NC-ND 4.0 International license.

Sporn et al. [14] suggested that reward could be used as a facilitatory mechanism to accelerate the lengthy learning process of coarticulation; however, our results contest this. In this study we found no effect of reward in either age group on coarticulation. Still, in our study, we only performed one day of testing. It has been shown that coarticulation can take weeks of practice to learn $[3,11]$ so it is feasible that we may have seen reward-based differences in coarticulation if we had tested participants on a further day, and this would still indicate an acceleration in coarticulation learning. ONR adults, whose MT improvements were not associated with coarticulation, maintained their performance after just 20 rewarded trials. The YNR group did not, despite their MT improvement being associated with increases in coarticulation, thus increased energetic efficiency. This refutes the proposition that motor improvements related to increased energetic efficiency become rewardindependent once learned [14], and goes against the hypothesis that older adults would employ the most energetically efficient mechanism, as their improvements were associated with increases in metabolic costs. Speculatively, it could be that young participants performance was reliant on usedependent plasticity (UDP; behaviour being shaped by recent experiences) which has been shown to be modulated by reward feedback [24]. As the YNR group were only exposed to reward for 20 trials, this may not have been enough to elicit any long-term changes in UDP; hence they reverted to their normal performance after reward was removed. Contrastingly, YR had experienced 220 rewarded trials and so did not revert to pre-reward levels of functioning. To test this theory further it would be interesting to either have more post-NR trials or another day of testing. This is because UDP has been associated with rapid decay [25] whereas improvements due to $\mathrm{Cl}$ are suggested to be long-lasting [14]. Although not causal, this does indicate that different mechanisms for motor improvement are being utilized by young and older adults, though it remains unclear why older adults are able to maintain performance improvements despite not showing association with a more energetically efficient mechanism. One suggestion is that older adults may have been improving their efficiency, but the $\mathrm{Cl}$ measure did not accurately assess this. $\mathrm{Cl}$ increases have been shown to be associated with alignment to a minimum jerk model of optimum performance [14], thus in this study it was assumed 
bioRxiv preprint doi: https://doi.org/10.1101/2021.09.27.461920; this version posted September 27, 2021. The copyright holder for this preprint (which was not certified by peer review) is the author/funder, who has granted bioRxiv a license to display the preprint in perpetuity. It is made available under aCC-BY-NC-ND 4.0 International license.

that $\mathrm{Cl}$ gave an insight into this alignment. However, as we did not explicitly assess minimum jerk alignment, it is feasible that increased alignment to the model may not be reflected in $\mathrm{Cl}$.

In conclusion, this work provides evidence that motivational modulation of sequential reaching is preserved across the lifespan. Although older adults showed typically slower movements, they were able to substantially improve their performance in the presence of reward. Further, they were able to maintain these performance improvements after reward was removed. We suggest that reward could be used as a compensatory mechanism for functional motor decline in healthy aging.

\section{References}

1. Doeringer, J.A. and N. Hogan, Serial processing in human movement production. Neural Netw, 1998. 11(7-8): p. 1345-1356.

2. Shah, A., A.G. Barto, and A.H. Fagg, A Dual Process Account of Coarticulation in Motor Skill Acquisition. Journal of Motor Behavior, 2013. 45(6): p. 531-549.

3. Sosnik, R., et al., When practice leads to co-articulation: the evolution of geometrically defined movement primitives. Exp Brain Res, 2004. 156(4): p. 422-38.

4. Dayan, P. and B.W. Balleine, Reward, motivation, and reinforcement learning. Neuron, 2002. 36(2): p. 285-298.

5. Manohar, S.G., et al., Reward Pays the Cost of Noise Reduction in Motor and Cognitive Control. Curr Biol, 2015. 25(13): p. 1707-16.

6. Summerside, E.M., R. Shadmehr, and A.A. Ahmed, Vigor of reaching movements: reward discounts the cost of effort. J Neurophysiol, 2018. 119(6): p. 2347-2357.

7. Codol, O., et al., Reward-Based Improvements in Motor Control Are Driven by Multiple ErrorReducing Mechanisms. J Neurosci, 2020. 40(18): p. 3604-3620.

8. Galea, J.M., et al., The dissociable effects of punishment and reward on motor learning. Nature neuroscience, 2015. 18(4): p. 597-602.

9. Gribble, P.L., et al., Role of cocontraction in arm movement accuracy. J Neurophysiol, 2003. 89(5): p. 2396-405.

10. Ortega, J.D. and C.T. Farley, Individual limb work does not explain the greater metabolic cost of walking in elderly adults. Journal of Applied Physiology, 2007. 102(6): p. 2266-2273.

11. Sosnik, R., et al., The acquisition and implementation of the smoothness maximization motion strategy is dependent on spatial accuracy demands. Experimental brain research, 2007. 176(2): p. 311-331.

12. Todorov, E. and M.I. Jordan, Smoothness maximization along a predefined path accurately predicts the speed profiles of complex arm movements. Journal of Neurophysiology, 1998. 80(2): p. 696-714.

13. Rohrer, B., et al., Movement smoothness changes during stroke recovery. J Neurosci, 2002. 22(18): p. 8297-304.

14. Sporn, S., X. Chen, and J.M. Galea, Reward-based invigoration of sequential reaching. bioRxiv, 2020.

15. Anwyl-Irvine, A., et al., Gorillas in our Midst: Gorilla.sc, a new web-based Experiment Builder. bioRxiv, 2018: p. 438242.

16. Alghamdi, A. and J.M. Galea, Pilot Study. 2021. 
17. Goggin, N.L. and G.E. Stelmach, Age-Related Differences in a Kinematic Analysis of Precued Movements. Canadian Journal on Aging / La Revue canadienne du vieillissement, 1990. 9(4): p. 371-385.

18. Weir, P.L., et al., Age-Related Differences in Prehension: The Influence of Task Goals. Journal of Motor Behavior, 1998. 30(1): p. 79-89.

19. Pratt, J., A.L. Chasteen, and R.A. Abrams, Rapid aimed limb movements: age differences and practice effects in component submovements. Psychol Aging, 1994. 9(2): p. 325-34.

20. Huang, J., M. Hegele, and J. Billino, Motivational Modulation of Age-Related Effects on Reaching Adaptation. Frontiers in Psychology, 2018. 9(2285).

21. Eppinger, B., et al., Reduced Striatal Responses to Reward Prediction Errors in Older Compared with Younger Adults. The Journal of Neuroscience, 2013. 33(24): p. 9905-9912.

22. Hämmerer, D., et al., Life span differences in electrophysiological correlates of monitoring gains and losses during probabilistic reinforcement learning. Journal of Cognitive Neuroscience, 2011. 23(3): p. 579-592.

23. Light, K.E. and W.W. Spirduso, Effects of adult aging on the movement complexity factor of response programming. Journal of Gerontology, 1990. 45(3): p. P107-P109.

24. Mawase, F., et al., Motor learning enhances use-dependent plasticity. Journal of Neuroscience, 2017. 37(10): p. 2673-2685.

25. Ruffino, C., et al., An acute session of motor imagery training induces use-dependent plasticity. Scientific reports, 2019. 9(1): p. 1-9. 